\title{
Eliminating occupational cancer in Europe and globally
}

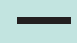

Jukka Takala

Working Paper 2015.10

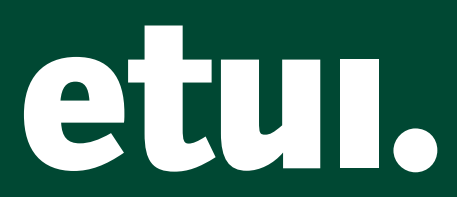




\section{Eliminating occupational cancer in Europe and globally}

-

Jukka Takala

Working Paper 2015.10 
Dr Jukka Takala is a senior consultant to the Ministry of Manpower, Singapore, and President of ICOH-CIST. Contact: jukka_takala@wshi.gov.sg

Contributions to this text were received from Eunice Yong, Ken Takahashi, Kurt Straif, Lesley Rushton, Sugio Furuya, John Cherrie, Rob Aitken, Midori Courtice, Laurent Vogel, Michel Héry, and many others.

Brussels, 2015

() Publisher: ETUI aisbl, Brussels

All rights reserved

Print: ETUI Printshop, Brussels

D/2015/10.574/51

ISBN: 1994-4446 (print version)

ISBN: 1994-4454 (electronic version)

$\star_{* \star \star}^{*}$ The ETUI is financially supported by the European Union. The European Union is not responsible for any use made of the information contained in this publication. 


\section{Contents}

Summary

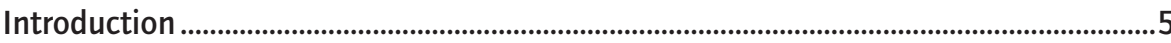

What we know about occupational cancer in a nutshell....................................................6

Incongruent estimates across reports .................................................................................

What are the cancers at work and what is the burden of occupational cancer?.........7

Occupational cancer in Europe.................................................................................................9

Exposures to occupational carcinogens, processes and jobs .......................................... 11

Asbestos exposure is the biggest killer ..........................................................................13

Likely underestimation of the magnitude of asbestos-related ill-health..................... 13

Recommendations, policy and practice ......................................................................... 17

Immediate outputs and methods...................................................................................... 18

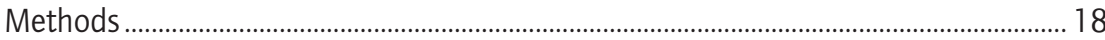

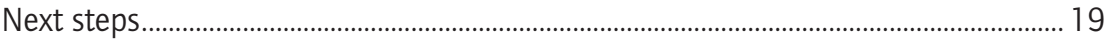

Conclusions for zero cancer at work......................................................................................2

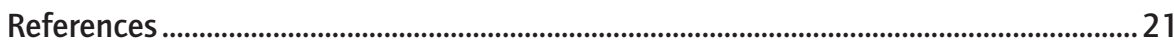




\section{Summary}

There is a need for clear priorities to prevent major work-related health risks and to identify solutions for action. Obviously, cancer at work is the biggest individual threat given the number of deaths in the EU and elsewhere in the developed world; this serious, but preventable disease is rapidly becoming the biggest killer at places of work in most countries. We can and should have a more ambitious target: to eliminate occupational cancer. This should be achieved via a gradual reduction of occupational exposures, in particular to carcinogens, substances and associated processes, arrangements and jobs that are known to cause or contribute to work-related cancers. This needs wide European and international collaboration to identify and market new and evidence-based policies and practices that have been shown to produce results. 


\section{Introduction}

The cancer epidemic is a major public health concern all over the world. There is an increasing awareness of the role of working conditions as a central determinant of social inequalities with regard to cancer. Twenty five years ago, the European Union adopted its first global directive for improving the workplace prevention of work-related cancer. At the time, it was an important contribution to modern legislation on workers' protection. For many stakeholders, it is time to adapt the legislation and the policy to the new knowledge and emerging risks. This working paper presents arguments for a stronger policy with an ambitious goal: the elimination of occupational cancer in Europe and globally. It presents a consistent estimation of the burden calculated on the basis of established exposures. It summarises the basic principles of effective prevention and calls for systematic action on the part of the various stakeholders. It assumes that occupational cancers are eliminable and that prevention could save many workers' lives and contribute considerably to the public health of European citizens. 


\section{What we know about occupational cancer in a nutshell}

\section{Incongruent estimates across reports}

Globally, cancer kills 8.2 million people each year and 14 million new cancers are detected every year, according to WHO/IARC. Mortality will increase 78 per cent and incidence 70 per cent by 2035. In the EU28, there were a predicted 1.314 million cancer deaths in 2013. While cancer is a multifactorial disease and some causal factors are difficult to modify, it is clear that cancers caused by work can be prevented by reducing or eliminating the exposures leading to the disease. In fact these cancers are the easiest ones to tackle: 'such risks can usually be reduced or even eliminated' (Doll 1981) and of course ethically there is no option.

The International Labour Organisation (ILO) estimates that 666,000 deaths are caused by occupational cancer globally every year, double that of occupational accidents. In the European Union (EU28), 102,500 deaths take place each year, twenty times the number caused by occupational accidents.

There is no doubt that cancer is the biggest killer at work in high income countries (WHO Classification), including the EU. Lung cancer counts for 54-75 per cent of all occupational cancer. Epidemiological studies indicate that occupational exposures cause $5 \cdot 3-8.4$ per cent of all cancers and among men 17-29 per cent of all lung cancer deaths, according to best estimates. Asbestos accounts for 55-85 per cent of lung cancer and causes other cancers and asbestos-related diseases today, which could have been prevented in the past. Of the 102,500 occupational cancer deaths in the EU28, asbestos causes between 30,000 - an old estimate - and 47,000 (based on this paper) every year, and the numbers are still rising. Cancer and occupational cancer mortality is increasing due to growing life expectancy and gradual reduction of other causes of death, such as communicable diseases and injuries. Work exposures cause cancers that have a high case mortality rate, such as lung cancer. The 10 most important occupational carcinogens count for around 85 per cent of all occupational deaths. 


\section{What are the cancers at work and what is the burden of occupational cancer?}

Doll and Peto estimated in 1981 that 4 per cent of all cancer deaths and 12.5 per cent of lung cancer deaths were caused by work. These were underestimates in light of present knowledge and gradually increasing number of carcinogens recognised by IARC (Doll and Peto 1981, Rushton et al. 2008). About 17-29 per cent of all lung cancer among men is due to occupational exposure and lung cancer accounted for 54-75 per cent of occupational cancer (Straif 2008).

The latest global data released by the ILO indicate that some 666,000 fatal work-related cancers occur every year, based on information from 2010 and 2011 (Nenonen et al. 2014). Records from 2008 gave an estimation of 610,000 occupational cancer deaths globally (Takala 2014). While these two sets of figures are consistent, the Institute of Health Metrics (IHME), which is located in the United States and has collected global data, including WHO reports - although the WHO has not endorsed the data - lists 304,000 workrelated deaths annually as caused by selected carcinogens (Forouzanfar et al. and Murray et al.), compared with 159,000 caused by occupational accidents. The ILO has another estimate of 353,00o deaths per year for fatal occupational accidents.

Furthermore, an IHME and Lancet ${ }^{1}$, (Stephen 2012) publication reported that 20,660 people were killed by occupational carcinogens per year while at work in western Europe (including the EU15, and Norway and Switzerland) but this figure is difficult to reconcile with a UK study recently published in BJC (Rushton 2012) that estimated 8,010 deaths from occupational cancer annually in Britain alone. The French President François Hollande launched an action plan saying: 'There are work-related cancers that affect at least 14,000 people each year. Two million are regularly exposed to carcinogenic chemicals (in France).'2 Another set of figures on the EU estimates, based on ILO methodology, indicates that in 2008 there were 82,000 and 95,000 fatal occupational cancers per year in the EU15 and the EU27, ${ }^{3}$ respectively.

1 IHME: http://www.healthmetricsandevaluation.org/gbd/visualizations/gbd-causepatterns

2 An update of the estimates of cancers attributable to occupational exposure in France, using tools developed by the French Institute for Public Health Surveillance, recently revised upwards the number of cases connected to asbestos exposure, mostly due to the inclusion of new cancers, such as laryngeal and ovarian cancers.

3 See: https://osha.europa.eu/data/links/occupational-and-environmental-cancerprevention-conference-presentations 
Figure 1 Global estimated work-related fatalities by region, absolute numbers

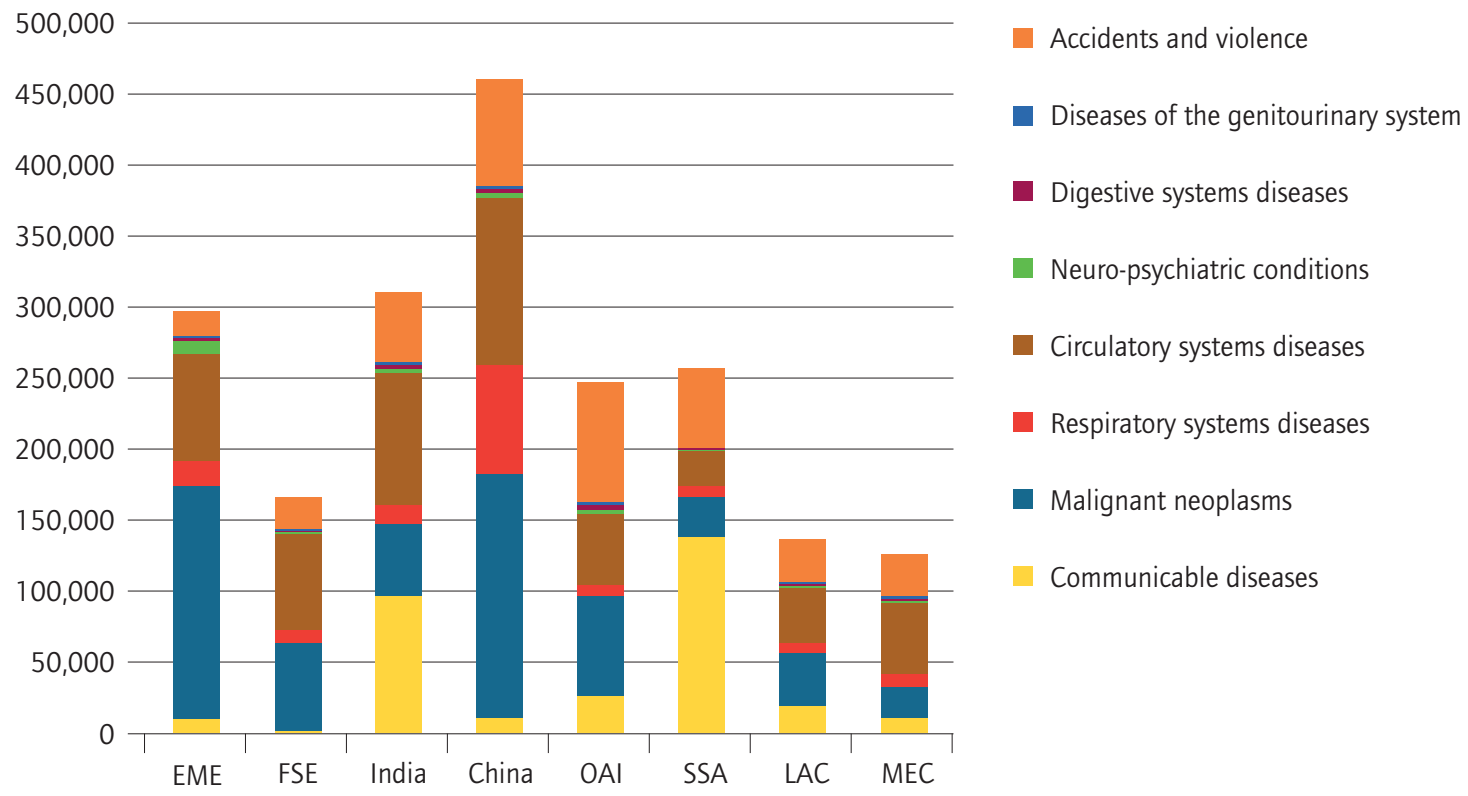

Wold Bank Regions: EME - Established Market Econimies: FSE - Former Socialist Economies: IND - India: CHN - China: OAI - Other Asia and Island: SSA - Sub-Saharian Africa: LAC - Latin-America and Caribbean: MEC - Middle Easter Crescent

Source: Nenonen et al. 2014.

Figure 2 Burden caused by cancer and other work-related diseases by WHO regions, released in 2014. Total number of workplace fatalities was 2.3 million

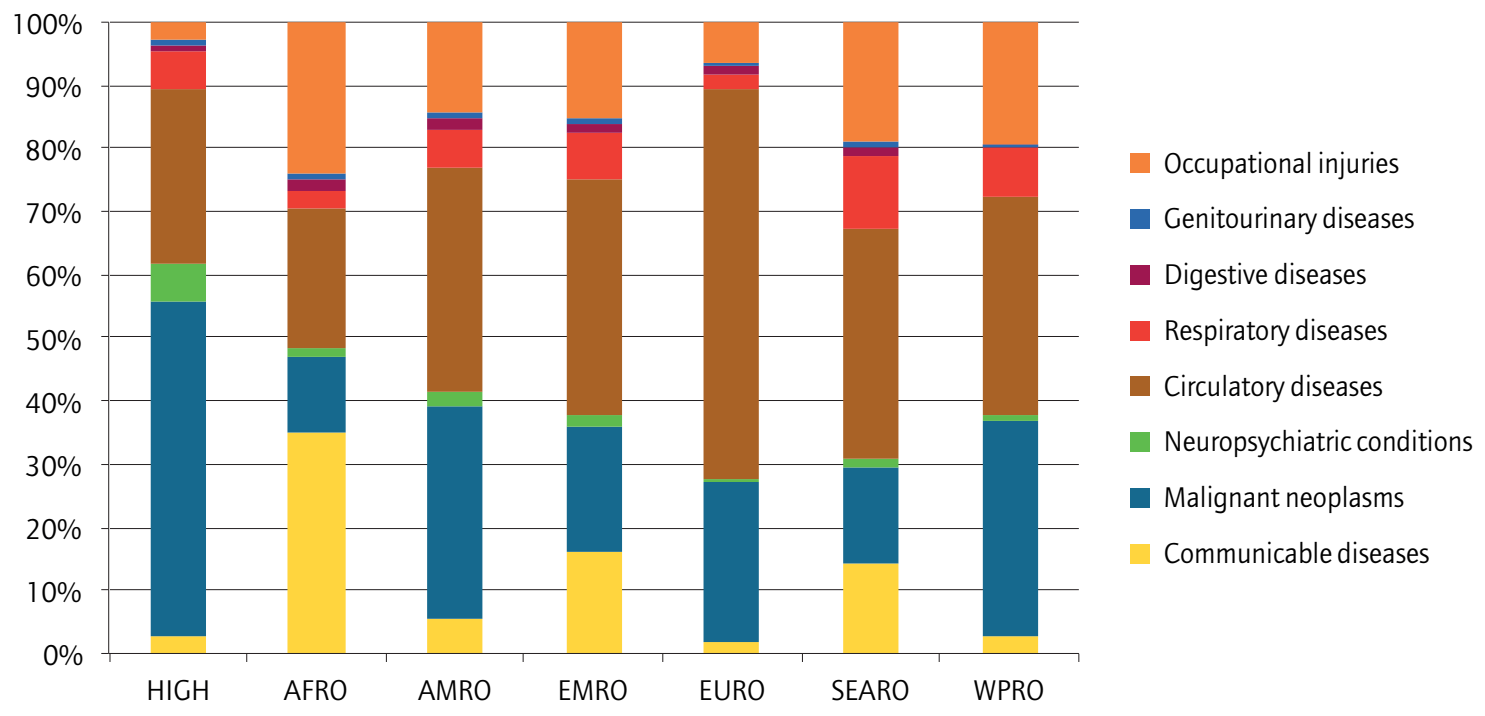

HIGH - High income countries, AFRO - African Region (low-and middle-income countries), AMRO - Region of the Americas (low-and middle-income countries), EMRO - Eastern Mediterranean Region (low-and middle-income countries), EURO - European Region (low-and middle-income countries), SEARO - South-East Asia Region (low-and middle-income countries), WPRO - Western Pacific Region (low-and middle-income countries) 


\section{Occupational cancer in Europe}

The ILO Global Estimates and corresponding attributable fractions in high income countries in the WHO classification - which includes the United States and Canada in North America, most European Union countries, Japan, Australia, New Zealand and Singapore, among others - came to 212,000 deaths caused by malignant neoplasms (occupational cancers) based on WHO mortality data in 2011. In a recent report made for the Greek Presidency Conference on Occupational Safety and Health in 2014 the EU share of this was 102,500 deaths (Takala 2014). The latest data released at the ILO-ISSA World Congress in August 2014 confirm this estimate in the EU28 based on 2010 and 2011 data from the WHO and the ILO.

Figure 3 Work-related annual deaths in the EU28 and other developed countries
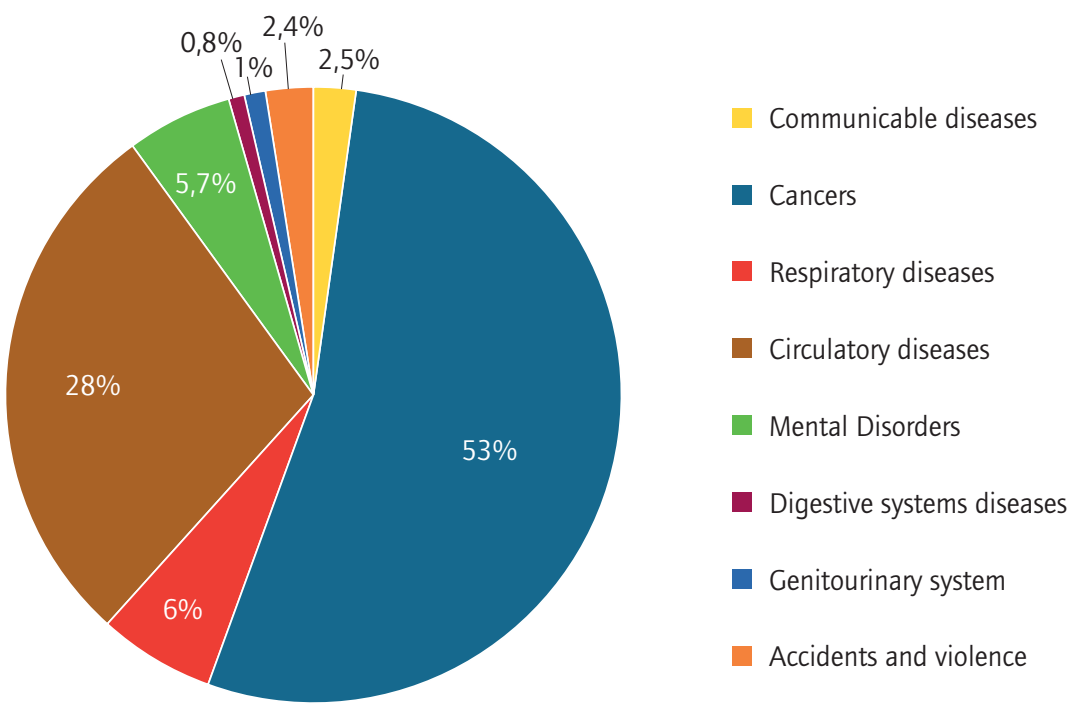

Previous global estimates on occupational cancers by the ILO established that 32 per cent of the deaths in the world related to work are associated with cancers (Takala 2005). However, occupational cancers are quite rapidly being globalised and in many industrialising countries the percentage of occupational cancer deaths among all work-related deaths approaches that of the high-income countries; for example, in the EU occupational cancer deaths are already at 53 per cent of all work-related deaths (see Figure 3), a small proportional decline from 57 per cent due to the slightly increased 
share of circulatory diseases (Takala et al. 2014). The standardised incidence rate (SIR), Relative Risk (RR) and consequently the attributable fraction, morbidity and mortality from various cancer forms vary widely between occupations, as shown in the study covering 15 million people and 45 years follow-up period using Nordic cancer registers. (Pukkala et al. 2009)

An approximate breakdown by EU member state of the 102,500 occupational cancer deaths is presented in Table 1. This estimate does not take into account the varying exposure level estimates in each member state and is based on European level data. For a more accurate estimate, however, detailed exposure data and a new EU CAREX database would be needed. These are not available at present. There is an urgent need to harmonise the estimation methods by various bodies and to resolve these issues. However, experience shows that the more we study occupational carcinogens, mutagens and reprotoxic substances, the higher the estimates of negative outcomes are likely to be. The need for further research cannot be used as an excuse for doing nothing: with today's solutions, most or all of such deaths and lost years of life can be eliminated.

Table 1 Rough division of occupational cancer by EU28 member states and subterritories within the EU in 2011

\begin{tabular}{|l|r|}
\hline Country & $\begin{array}{l}\text { Occupational } \\
\text { cancer deaths }\end{array}$ \\
\hline Andorra & 17 \\
\hline Austria & 1820 \\
\hline Belgium & 2079 \\
\hline Bulgaria & 1445 \\
\hline Croatia & 742 \\
\hline Cyprus & 179 \\
\hline Czech Republic & 2238 \\
\hline Denmark & 1242 \\
\hline Estonia & 292 \\
\hline Finland & 1135 \\
\hline France & 12035 \\
\hline Germany & 17706 \\
\hline Gibraltar & 5 \\
\hline Greece & 2131 \\
\hline Greenland & 14 \\
\hline Guernsey & 13 \\
\hline Hungary & 1808 \\
\hline Ireland & 928 \\
\hline Isle of Man & 18 \\
\hline
\end{tabular}

\begin{tabular}{|l|r|}
\hline Country & $\begin{array}{l}\text { Occupational } \\
\text { cancer deaths }\end{array}$ \\
\hline Italy & 10609 \\
\hline Jersey & 23 \\
\hline Latvia & 491 \\
\hline Lithuania & 694 \\
\hline Luxembourg & 98 \\
\hline Malta & 75 \\
\hline Monaco & 21 \\
\hline Netherlands & 3721 \\
\hline Poland & 7501 \\
\hline Portugal & 2371 \\
\hline Romania & 4233 \\
\hline San Marino & 0 \\
\hline Slovakia & 1150 \\
\hline Slovenia & 442 \\
\hline Spain & 9807 \\
\hline Sweden & 2103 \\
\hline United Kingdom & 13330 \\
\hline Total EU & 102,517 \\
\hline
\end{tabular}




\section{Exposures to occupational carcinogens, processes and jobs}

There are 179 agents (chemicals or exposure circumstances) classified by the International Agency for Research on Cancer (IARC in Lyon, France) as known or probable human carcinogens, Groups 1 and 2a, respectively. There are another 285 agents classified as possible human carcinogens, Group 2b. ${ }^{4}$ A large proportion of these agents are found at work or present in the workplace, such as environmental tobacco smoke. Indications exist that other substances, agents and processes are also carcinogenic, as demonstrated by recent important additions to the list, for example, diesel engine exhaust. There is also a possibility that endocrine disruptors play a role in hormonerelated cancers. Gender factors should be further studied, too (Mengeot et al. 2014). The IARC list of classified carcinogens needs to be continually revised and the precautionary principle applied.

A hierarchy of elimination and control protocols exists to protect workers from exposure to these agents and in theory occupational cancer could be completely preventable. However, cases of work-related cancer are still occurring. The proportion of cancer deaths attributable to occupational causes in Finland was 8.3 per cent (13.2 per cent among males), and in the United Kingdom it was 5.3 per cent (8 per cent among males), which equates to 8,010 cancer deaths and nearly 14,000 cancer cases. Current estimates of occupationally related cancers result from exposures to hazardous agents many decades ago, but hazardous substances continue to be found in the workplace and pose a risk of future disease. Some substances, such as silica and diesel engine exhaust, are process-generated and remain to be regulated differently, while other things, such as shift-work, are relatively new risks which need to be better managed at workplaces and regulated under occupational safety and health rules.

In order to obtain a comprehensive picture of occupational exposures, cancer exposure registers (CAREX) and job exposure matrices (JEM) have been established in many countries and regions, such as Finland, Canada ${ }^{5}$ and the EU. (Kauppinen 2012, 2000)

One way to estimate exposures is to investigate the current prevalence of occupational exposure to carcinogens by interviewing a random population of working age men and women in a geographical area, such as the Australian Work Exposures Study (Carey et al. 2014). Periodic national surveys of industrial exposure can also usefully add to the available intelligence, like those

4 See: http://monographs.iarc.fr/ENG/Classification/index.php (accessed 17 March 2014).

5 CAREX Canada, see http://www.carexcanada.ca/en/occupational_approach/ (accessed 17 March 2014). 
carried out in the United Kingdom (Unwin 2006). Additionally, information about temporal trends in exposure can help to improve our understanding of the effectiveness of control programmes within and between countries (Creely et al. 2007; Agostini 2010). Measuring lifetime exposures and related cancer cases by occupations in registers, such as in the Nordic study (Pukkala et al. 2009), would be important as long as access to individual data is difficult. National or industry-wide exposure data linked to population-based casecontrol studies and self-reported surveys by occupations may add to the picture.

Figure 4 Most frequent carcinogens and exposures at work in the United Kingdom

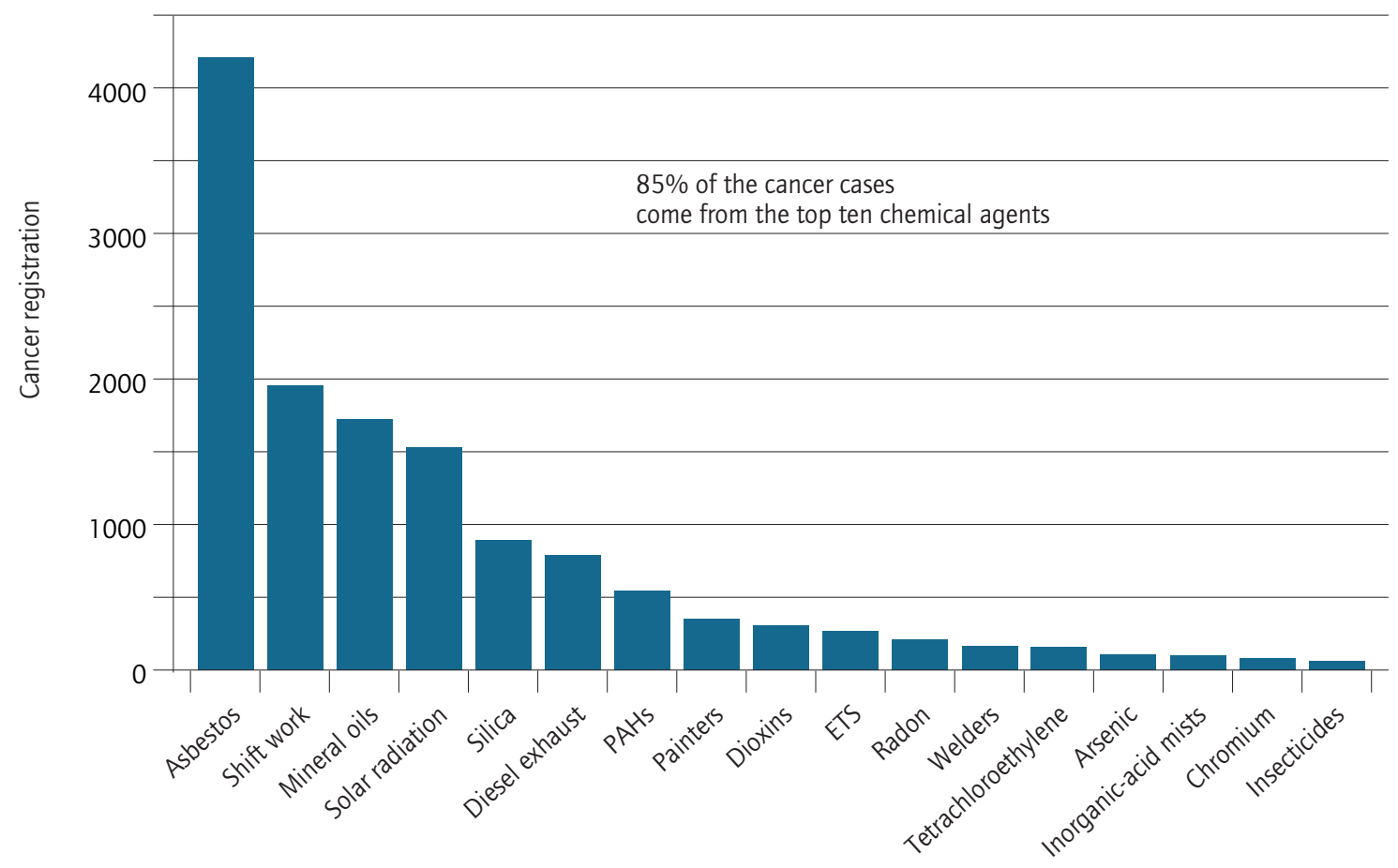

Occupational carcinogens affect 1 in 5 workers in the EU, based on EU CAREX (Carcinogen exposure database), or 23 per cent of those employed are exposed to carcinogens (Kauppinen 2000). The corresponding figure according to a recent study in Canada was 43 per cent (Peters et al. 2014) and in Australia (Carey 2014) 37.6 per cent. A larger group of workers exposed at lower levels and with a lower risk of disease will also contribute to overall disease burden (Straif 2012). Exposures must be controlled by measures that are proportional to the risk of disease. It is therefore important to know the proportion of workers exposed to hazardous substances and how exposure levels and patterns differ among those exposed in order to explicitly target the areas that contribute most to disease and determine where priority action is required. The IRSST Institute in Quebec has launched practical publications to identify carcinogens at work (Labrèche 2013). 


\section{Asbestos exposure is the biggest killer}

\section{Likely underestimation of the magnitude of asbestos- related ill-health}

On asbestos-related mortality, some years ago the WHO gave an estimate of 107,000 cases, ${ }^{6}$ while the ILO and the EU estimated this as $100,000^{7}$ and 112000 deaths ${ }^{8}$ per year, respectively. Although these are largely congruent, based on the latest research, it indicates that the number of asbestosinduced lung cancers has been underestimated in the IHME numbers. Using mesothelioma as a proxy for asbestos exposure, McCormack et al. have shown that, depending on the type of asbestos used, the number of lung cancers in relation to mesothelioma is between 2 and 10 times that of mesothelioma cases, the mid-point being 6.1 lung cancers for every mesothelioma death (McCormack et al. 2012).

In individual countries - for example, Finland - the ratio between mesothelioma and lung cancer caused by asbestos has been estimated at about 1:4 due to antophyllite asbestos. In 2001 the point estimate was 42 work-related and altogether 59 mesotheliomas. Including lung cancers: 208 lung cancer deaths and 42 mesotheliomas, totalling 250 deaths - other cancer sites not included - were caused by asbestos from the total of 839 all work-related cancer deaths (Nurminen and Karjalainen 2001) in about a 2.1 million workforce. However, in 2010 the registered number in Finland was 91 mesotheliomas (Finnish Institute of Occupational Health 2013). Comparing the estimated number of all occupational cancer deaths in Finland with the United Kingdom, Finland has a working population of slightly less than 10 per cent of that of the United Kingdom. Rushton's estimate for the United Kingdom in 2005 was 4,216 for all asbestos-related occupational cancers, of which there were 1,937 mesotheliomas, and 8,010 occupational cancer deaths in total. Mesothelioma is much more commonly accepted as compensatable, while lung cancers caused by asbestos are not well - or often not at all registered or compensated due to multiple causes and the lower work-related attributable fraction (AF). In national compensation practice the required level of the causal factor is often more than 50 per cent of all causes corresponding

6 WHO: http://www.who.int/ipcs/assessment/public_health/asbestos/en/

7 ILO: www.ilo.org/global/about-the-ilo/newsroom/features/WCMS_076282/lang--en/ index.htm

8 See: http://www.efbww.org/pdfs/Presentation\%2oMr\%20Takala.pdf (accessed 17 March 2014) 
to relative risk $\mathrm{RR}=$ 2.o. Furthermore, it is often very difficult to individualise the disease burden.

The ratio between mesothelioma and work-related lung cancer commonly used in the past was 1:1. For example, Rushton (Rushton et al. 2012) estimated that there were 1,937 mesothelioma deaths and 2,223 asbestos-related lung cancer registrations and deaths caused by asbestos in the United Kingdom in 2004 and that these numbers are still growing. If the lung cancer numbers are radically higher - as it appears they are - lung cancer estimates caused by asbestos alone go far beyond the figures caused by carcinogens as reported by the Global Burden of Disease and Injury process presented by the IHME visualisations. A comprehensive picture of asbestos exposures causing lung cancers, mesothelioma and other cancers, such as larynx, ovary and possibly colorectal cancers, should be properly investigated using CAREX exposure estimates and job exposure matrices.

However, this cannot be realistically carried out in every country soon. A reasonable proxy for asbestos exposure will be the asbestos consumption in tonnes of asbestos used in a country or region. The consumption of asbestos has been surprisingly similar in most countries and some two-thirds of asbestos has been used for asbestos-cement products, such as roofing, wall materials and water pipes. The rest of asbestos has been used for brake pads, heat insulation, gaskets and so on. International comparison has shown that, in average, every 170 tonnes of asbestos used in a country causes one mesothelioma death (Tossavainen 2004).

Using a similar proxy as above on the correlation with asbestos consumption in tonnes and asbestos-related lung cancer deaths (ARLC) as for mesothelioma, the estimate, based on $\mathrm{RR}=2.3$ for asbestos-related lung cancer and attributable fraction, $\mathrm{AF}=13.8$ per cent for males, 2.2 per cent for females, the ratio between mesothelioma and ARLC will be 1:3.5 (1:3.5254 based on above data), still well below the average 1:6.1 given by McCormack et al. As a result, every 48 tonnes of asbestos consumption causes one ARLC death.

The latest data based on WHO crude mortality rates, CMR, compiled by the team of Prof. Ken Takahashi (Kameda et al. 2014) of University of Occupational and Environmental health in Japan, UOEH, indicate that the crude mortality rate, CMR, mid-point estimate is 8.o per million for mesothelioma globally. However, the CMR for European Union Member States EU28 would be 18.50 deaths per million population based on 27 member states (Greek data were missing from WHO data). ${ }^{9}$ While using this number may cause both over-estimation and under-estimation due to data extrapolation to the whole EU population - 501 million in 2010 - the outcome would be sufficiently reliable if the countries were divided into two groups: (i) high mesothelioma countries (United Kingdom, Netherlands and Italy) using their latest specific CMR for mesothelioma rates and population, and (ii) all the rest having average mesothelioma CMR.

9 Takahashi Ken, private communication, January 2015. 
Globally there could be one or more groups of relatively low mesothelioma rates, such as those in Asia (except for Japan, which has an average mesothelioma rate; see Figure 5).

As a result there would be:

- 4,306 mesothelioma total deaths in the United Kingdom $(2,423)$, the Netherlands (481) and Italy $(1,402)$, using the actual number of reported mesothelioma deaths in these countries, a rate of 31.5 per million population, and

- 6,062 mesothelioma deaths in the rest of the EU28, based on 501 million EU28 population and an average EU27 rate of 16.6 per million population (8,191 deaths out of the EU27 population of 492,118,400; Greece data are missing from WHO data but included in the 501 million EU data), totalling 10,368 mesothelioma deaths in the EU28. The global mesothelioma deaths were estimated to be in the range of 31,000-39,000,35 while the latest Global Burden of Disease study in 2013 estimated 33,700 deaths.

The asbestos-related lung cancer deaths for the two groups are:

- 15,180 asbestos-related lung cancer deaths in the United Kingdom, the Netherlands and Italy, and

- 21,371 asbestos-related lung cancer deaths in the rest of EU28, totalling

- 36,551 asbestos-related lung cancer deaths in the EU28 in 2010.

The combined number of deaths will amount to 46,919 lung cancer and mesothelioma deaths caused by asbestos, which still misses other workrelated cancers caused by asbestos, such as larynx and ovary, and possibly stomach, colorectal and pharynx cancers. The traditionally low crude mortality ratio between mesothelioma and ARLAC used in the United Kingdom in the past would result in a total number of 26,000 asbestos-related lung cancer and mesothelioma deaths in EU28. Other cancers and asbestosis are adding to the death toll caused by asbestos.

One should keep in mind that it is not just the exposure in the past that creates problems. Asbestos, in particular, will be present in European working life for decades in the future, requiring proper regulatory measures and management of existing structures, devices and equipment, and removal operations.

In Figure $5 \mathrm{I}$ have used the $\mathrm{RR}=2.3$ and $\mathrm{AF}=13.8$ per cent for males, 2.2 per cent for females for asbestos-related lung cancer in Finland and the United Kingdom (numbers from the Health and Safety Executive). 
Figure 5 Mesothelioma and related asbestos-related lung cancer mortality and proposed groups

U.K.: 2750 a-r lung cancers, 43.2 /mill. 2535

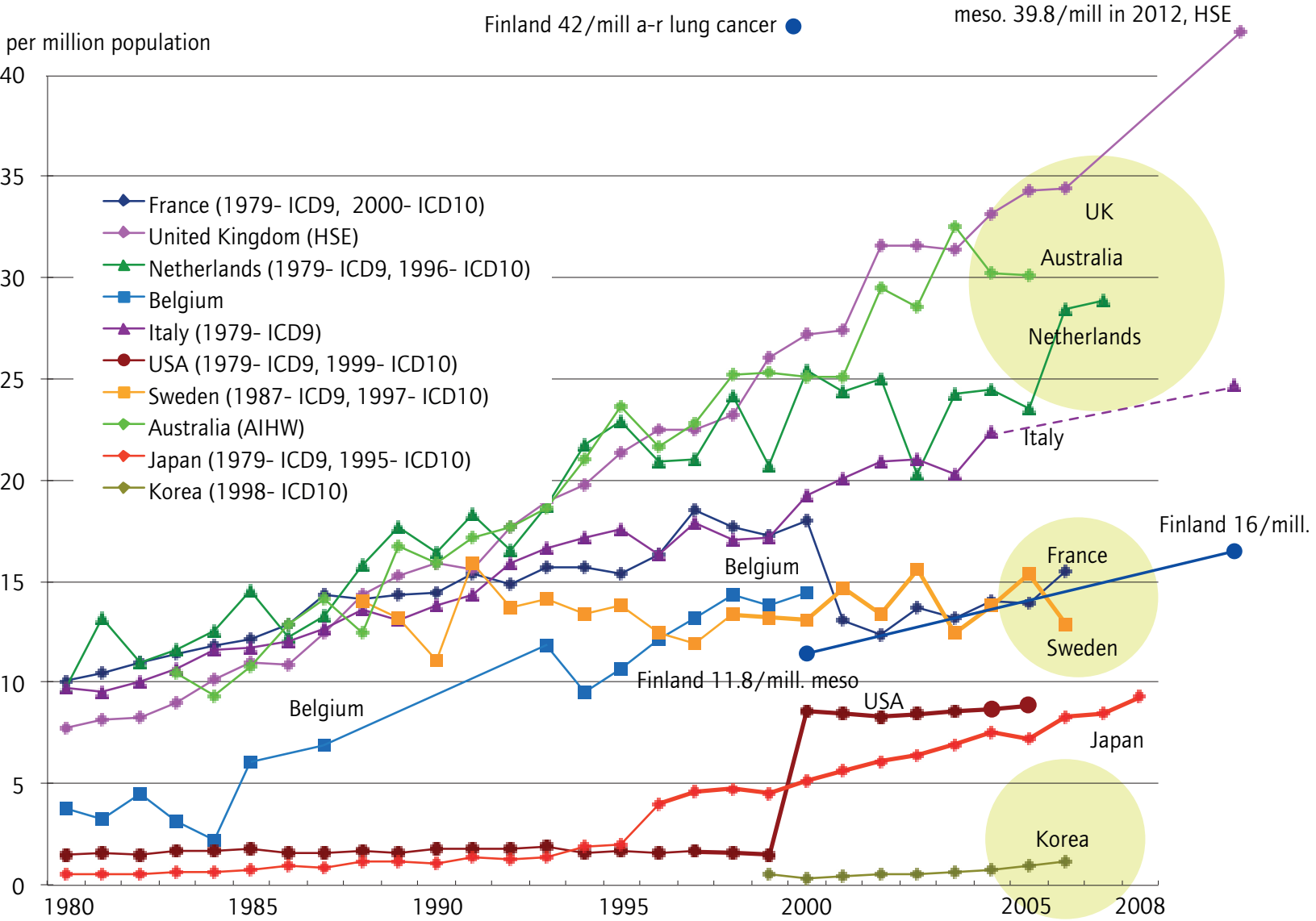

WHO Mortality Database, ICD 10: C45 Mesothelioma, ICD 9: 163 Malignant Neoplasm of Pleura

UK: HSE Statistics - Mesothelioma, http://www.hse.gov.uk/statistics/causdis/mesothelioma/

Australia: National Cancer Statistics Clearing House of Australian Institute of Health and Welfare (AIHW)

Sources: Figure elaborated by Sugio Furuya, additions by Takala and Goh 2014. The last figure for Italy is taken from Takahashi et al. 


\section{Recommendations, policy and practice}

(i) We need to influence and advocate measurable and continuous reduction of exposures caused by work globally and across regions in order to eliminate occupational cancer.

(ii) An international programme should be launched on the 'Elimination of occupational cancer' following the WHO model of elimination of smallpox from the world and present programmes to 'eliminate asbestosrelated diseases', and to 'eliminate silicosis'.

(iii) The EU must be a key driver for such programme, while the ILO and the WHO and all relevant organisations, including professional organisations, should be linked. This could be done by full implementation of the REACH programme prioritising substitution of carcinogenic, mutagenic and reprotoxic substances in the authorisation and restriction processes. Also advisable are revising worker protection legislation, setting binding occupational exposure limits and ensuring enforcement related to specific exposure of carcinogens, such as crystalline silica, diesel exhaust and wood dust, listed in Figure 4 above. The European Union has a key role as a major world producer of chemical products. The EU also has relatively strong regulatory power and can set policy models for eliminating occupational cancer. A comprehensive set of conclusions and recommendations is given in the European Risk Observatory Report on Exposure to Carcinogens and Work-related Cancer. (European Agency for Safety and Health at Work 2014) 


\section{Immediate outputs and methods}

Present unified scientific evidence of the magnitude of the problems, levels of exposures and numbers of workers exposed, as well as credible data on predicted negative outcomes.

Provide recommendations on evidence-based solutions that are adaptable to different kinds of circumstances, cultures, countries, sectors and sizes of workplaces.

Share findings via well-prepared reports and articles published in high impact journals.

Mobilise European institutions and European member states to act on the elimination of work-related cancer and expand this action gradually through the ILO and its Occupational Safety and Health Flagship programme currently being established, and through the WHO and its' collaboration centres' network, supporting IARC efforts in this field, and mobilising global action through national stakeholders.

\section{Methods}

(i) Establish open and transparent collaboration starting from credible and trusted sources of information, including international organisations, associations, institutions and researchers.

(ii) Set up a foundation and other sources of funding for research and action to eliminate work-related cancer.

(iii) Identify key scientifically substantiated and commonly accepted evidence, as well as disagreements or conflicting information.

(iv) Critically review, compile and produce widely supported papers, reports and scientific evidence related to the problem.

(v) Disseminate, publicise and promote the knowledge in an easily understandable and convincing manner, via credible organisations, the media, publications and readily accessible authoritative data sources. The recent Institution of Occupational Safety and Health (IOSH) - based in the United Kingdom but with a global network - campaign 'NO TIME TO LOSE' is a great example of such a programme. (IOSH 2014) 
(vi) Ban asbestos use globally. Radically restrict other use of carcinogenic, mutagenic and reprotoxic materials, stop critical processes and modify jobs. Manage and regulate closely asbestos in existing buildings, structures and devices.

(vii) Use global and regional networks to convince the ILO, the WHO and the $\mathrm{EU}$ and their member states to adopt and endorse the programme.

\section{Next steps}

This proposed collaboration intends to gather interested parties to:

(i) Establish an international action programme, including regional action - for example, in the EU - to eliminate cancer at work through the identification and elimination of exposures to carcinogenic, mutagenic and teratogenic substances and agents, and modification of related work processes.

(ii) Mobilise ILO, WHO and EU member states to set up similar country programmes in collaboration with all relevant stakeholders and, in particular, involving workers and employers and their organisations.

(iii) Persuade the ILO and the WHO to join the programme using the same models as past ILO/WHO programmes.

(iv) The European Agency for Occupational Safety and Health and the European Commission should jointly support such action in the EU.

(v) Draft scientific papers, guidance and reports on occupational cancer and ways to reduce and eliminate exposures. Rather than relying on individual researchers of institutions a network of collaborators should be established to contribute.

(vi) Once reasonable findings are complete, these need to be endorsed by credible research bodies, authorities and organisations to provide sufficient weight for further action. These include key institutes, government administrations, workers and their organisations, including trade unions, employers' organisations, sectoral industry associations, and international and regional players, environmental NGOs and associations, such as ICOH, IOHA, AIHA, ISSA, IOSH, IALI, Collegium Ramazzini.

(vii) A group of focal points and interested bodies and experts will be needed to participate in drafting and/or peer reviewing the outputs. Any interested stakeholder may identify such network members. 


\section{Conclusions for zero cancer at work}

(i) Asbestos exposure is a demonstration of how poor and slow decisions in the past related to exposures to carcinogens created a serious epidemic. More ambitious targets for the future are needed because a large percentage of workers are still exposed to carcinogens even in countries where asbestos has been banned.

(ii) The EU has unique opportunities because it has legislative powers in several interlinked areas, such as those related to production and marketing of chemical products, workers' protection and environmental issues.

(iii) International cooperation can help a lot to avoid losing time. If we want to promote an ambitious programme for 'zero work-related cancer', cooperation between the EU, the WHO, the ILO and other institutions would be crucial. It is vital to avoid exporting the risks from developed to developing countries. 


\section{References}

Agostini M., de Vocht F., van Tongeren M., Cherrie J., Galea K. S. and Kromhout H. (2010) Exposure to rubber process dust and fume since 1970s in the United Kingdom; influence of origin of measurement data, Journal of Environmental Monitoring, 12 (5), 1170-1178.

Carey R., Driscoll T., Peters S., Glass D., Reid A., Benke G. and Fritschi L. (2014) Estimated prevalence of exposure to occupational carcinogens in Australia (2011-2012), Occupational \& Environmental Medicine, 71 (1), 55-62.

Carey RN., Driscoll TR., Peters S., Glass DC., Reid A., Benke G. and Fritschi L. (2014) Estimated prevalence of exposure to occupational carcinogens in Australia (2011-2012), Occupational \& Environmental Medicine, 71 (1), 55-62. doi: 10.1136/oemed-2013-101651

Creely K. S., Cowie H., van Tongeren M., Kromhout H., Tickner J. and Cherrie J. (2007) Trends in inhalation exposure--a review of the data in the published scientific literature, The Annals of Occupational Hygiene, 51 (8), 665-678. doi:10.1093/annhyg/ mem050

Doll R. and Peto R. (1981) The causes of cancer: quantitative estimates of avoidable risks of cancer in the United States today, Journal of the National Cancer Institute, 66 (6), 1192-1308.

European Agency for Safety and Health at Work (2014) Exposure to carcinogens and work-related cancer, A review of assessment methods. European Risk Observatory Report, Luxembourg, Publications Office of the European Union. https://osha.europa. eu/en/publications/reports/report-soar-work-related-cancer

Finnish Institute of Occupational Health (2013) Memorandum from the Occupational Cancer Working Group 2013, Helsinki. http://www.ttl.fi/en/publications/electronic_publications/pages/memorandum_cancer.aspx

Forouzanfar M.H. et al. (2015) Global, regional, and national comparative risk assessment of 79 behavioural, environmental and occupational, and metabolic risks or clusters of risks in 188 countries, 1990-2013: a systematic analysis for the Global Burden of Disease Study 2013. The Lancet, 10 Sep 2015. DOI: http://dx.doi.org/10.1016/S01406736(15)00128-2, http://www.thelancet.com/journals/lancet/article/PIIS01406736(15)00128-2/abstract

IOSH Campaign "No Time To Lose" launched in November 2014. http://www.notimetolose.org.uk/News-and-events/Occupational-cancer-sufferers-back-new-IOSH-campaign.aspx

Kameda T., Takahashi K., Kim R., Jiang Y., Movahed M., Park EK. and Rantanen J. (2014) Asbestos: use, bans and diseases burden in Europe, Bulletin of the World Health Organization, 92 (11), 790-797. doi: http://dx.doi.org/10.2471/BLT.13.132118

Kauppinen T., Toikkanen J., Pedersen D. et al. (2000) Occupational exposure to carcinogens in the European Union, Occupational \& Environmental Medicine, 57 (1), 10-18. doi: $10.1136 /$ oem.57.1.10 
Kauppinen T. (2012) Burden or work-related cancer in Finland and two exposure information systems (CAREX and FINJEM) including estimates of occupational exposure to carcinogens. EU-OSHA Seminar, Berlin 2012. http://www.beswic.be/en/seminars/workshop-on-carcinogens-and-work-related-cancer/speech-venues/sessiona-methods-to-assess-exposure-to-carcinogens-and-the-work-related-cancer-burden/ the-burden-of-work-related-cancer-in-finland-and-two-exposure-information-systemscarex-and-finjem-including-estimates-on-occupational-exposure-to-carcinogens; and: https://osha.europa.eu/en/seminars/workshop-on-carcinogens-and-work-related-cancer/speech-venues/session-a-methods-to-assess-exposure-to-carcinogens-andthe-work-related-cancer-burden/the-burden-of-work-related-cancer-in-great-britain

Kauppinen T., Toikkanen J., Pedersen D., Young R., Ahrens W.,Boffetta P., Hansen J., Kromhout H., Maqueda Blasco J., Mirabelli D., de la Orden-Rivera V., Pannett B., Plato N., Savela A., Vincent R. and Kogevinas M. (2000) Occupational exposure to carcinogens in the European Union, Occupational \& Environmental Medicine, 57 (1), 10-18.

Labrèche F. et al. (2013) Are there carcinogens in your workplace? It's time to act!, Montréal, Québec, IRSST, RG-796. www.irsst.qc.ca/media/documents/PubIRSST/RG-796. pdf

Labrèche F. et al. (2013) Y a-t-il des cancérogènes dans votre milieu de travail ? Passez à l'action !, Montréal (Québec), IRSST, RG-790. www.irsst.qc.ca/media/documents/ PubIRSST/RG-790.pdf

McCormack V., Peto J., Byrnes G., Straif K. and Boffetta P. (2012) Estimating the asbestosrelated lung cancer burden from mesothelioma mortality, British Journal of Cancer, 106 (3), 575-584. http://www.ncbi.nlm.nih.gov/pmc/articles/PMC3273352/

Mengeot A.M., Musu T. and Vogel L. (2014) Preventing work cancers, a workplace health priority, Brussels, European Trade Union Institute. http://www.etui.org/Publications2/Guides/Preventing-work-cancers.-A-workplace-health-priority

Murray C. et al. (2012) Disability-adjusted life years (DALYs) for 291 diseases and injuries in 21 regions, 1990-2010: a systematic analysis for the Global Burden of Disease Study 2010, The Lancet, 380 (9859), 2197-2223. http://thelancet.com/pdfs/journals/lancet/PIIS0140673612616894.pdf

Nenonen N., Hämäläinen P., Takala J., Saarela K.L., Lim S.L., Lim G.K., Manickam K. and Yong E. (2014) Global estimates of occupational accidents and fatal work-related diseases in 2014, Singapore, Workplace Safety \& Health Institute. http://goo.gl/UIZorD and http://goo.gl/tN7XDn

Nurminen M. and Karjalainen A. (2001) Epidemiologic estimate of the proportion of fatalities related to occupational factors in Finland, Scandinavian Journal of Work, Environment \& Health, 27 (3), 161-213. http://www.sjweh.fi/show_abstract.php?abstract_ id $=605$

Peters C.E., Ge C.B., Hall AL., Davies H.W. and Demers P.A. (2014) CAREX Canada: an enhanced model for assessing occupational carcinogen exposure, Occupational \& Environmental Medicine, Published Online First 26 June 2014, doi:10.1136/ oemed-2014-102286.

Pukkala E., Matinsen J.I., Lynge E., Gunnarsdottir H.K., Sparén P., Tryggvadottir L., Weiderpass E. and Kjaerheim K. (2009) Occupation and cancer - follow-up of 15 million people in five Nordic countries, Acta Oncologica; 48 (5), 646-790. http://informahealthcare.com/doi/pdf/10.1080/02841860902913546

Rushton L., Hutchings S. and Brown T. (2008) The burden of occupational cancer: estimation as the first step to prevention, Occupational \& Environmental Medicine, 65 (12), 789-800. 
Rushton L., Hutchings S.J., Fortunato L., Young C., Evans G.S., Brown T., Bevan R., Slack R., Holmes P., Bagga S., CherrieJ. W. and Van Tongeren M. (2012) Occupational cancer burden in Great Britain, British Journal of Cancer, 107 (S1), S3-S7. http://www.nature. com/bjc/journal/v107/n1s/index.html

Stephen S. Lim et al.(2012) A comparative risk assessment of burden of disease and injury attributable to 67 risk factor clusters in 21 regions, 1990-2010: a systematic analysis for the Global Burden of Disease Study 2010, The Lancet, 380 (9859), 2224-2260.

Straif K. (2012) Foreword: Estimating the burden of occupational cancer as a strategic step to prevention, British Journal of Cancer, 107, S1-S2; doi:10.1038/bjc.2012.135. http://www.nature.com/bjc/journal/v107/n1s/full/bjc2012135a.html

Takala J. (2005) Introductory report: Decent work - safe work: XVIIth World Congress on Safety and Health at Work, Geneva, ILO, 2005. http://ohsa.org.mt/Portals/0/docs/ intrep_05.pdf

Takala J. (2014) Work-related illnesses, identification, causal factors and prevention 'safe work - healthy work - for life', Greek EU Presidency Conference Athens, $16-17$ June 2014. www.gr2014.eu/sites/default/files/Work-related\%20IIInesses\%20Identification,\%20Causal\%20Factors\%20and\%20Prevention\%20"Safe\%20Work\%20-\%20 Healthy\%20Work\%20-\%20For\%20Life".pdf

Takala J. and Goh L. (2014) Asbestos - Trends and Action Globally and in Singapore. Presentation in the "Expedite Asia Free from Asbestos Hazard" Conference in Bangkok" on 24-25 Nov 2014. http://www.slideshare.net/jstakala/asbestos-thailand-conference2014-nov-singapore-j-takala-lynnette-goh-edited

Takala J., Hämäläinen P., Saarela K.L., Loke Y.Y., Manickam K., Tan W.J., Heng P., Tjong C., Lim G.K., Lim S. and Gan S.L. (2014) Global estimates of the burden of injury and illness at work in 2012, Journal of Occupational and Environmental Hygiene, 11, 32633. Taylor \& Francis, open access. http://www.tandfonline.com/doi/pdf/10.1080/ 15459624.2013 .863131

Tossavainen A. (2004) Global use of asbestos and the incidence of mesothelioma. International Journal of Occupational and Environmental Health, 10 (1), 22-25.

Unwin J., Cocker J., Scobbie, E. and Chambers H. (2006) An assessment of occupational exposure to polycyclic aromatic hydrocarbons in the UK, The Annals of Occupational Hygiene, 50 (4), 395-403.

All links were checked on 17 September 2015. 
